\title{
Effect of early supported discharge after stroke on patient reported outcome based on the Swedish Riksstroke registry
}

\author{
Anna Bråndal ${ }^{1,2^{*}}$, Marie Eriksson $^{3}$, Eva-Lotta Glader ${ }^{1}$ and Per Wester ${ }^{1,4}$
}

\begin{abstract}
Background: The efficacy of early supported discharge (ESD) has not been tested in current stroke care setting, which provide relatively short hospital stays, access to hyper-acute therapies and early carotid stenosis interventions. This study aimed to compare patient-reported outcome measures (PROM) among patients with stroke that received modern stroke unit care with or without ESD.

Methods: Observational study of 30,232 patients with first-ever stroke registered in the Riksstroke registry in Sweden, between 1 January 2010 and 31 December 2013. Patient characteristics were collected from the Riksstroke and Statistics Sweden databases. The primary outcome was satisfaction with the rehabilitation at 3 months after discharge. Secondary outcome were information about stroke provided, tiredness/fatigue, pain, dysthymia/ depression, general health status and dependence in activities of daily living (mobility, toileting and dressing) at 3 months after the stroke. We used separate multivariable logistic regression models for each PROM variable to analyze associations between PROMs and ESD/no ESD.
\end{abstract}

Results: The ESD group comprised 1495 participants: the control group comprised 28,737 participants. Multivariable logistic regression models of PROMs showed that, compared to controls, the ESD group was more satisfied with rehabilitation after discharge (OR: 1.78, 95\% Cl: 1.17-2.49), experienced less dysthymia/depression (OR: $0.68,95 \% 0.55-0.84$ ) and showed more independence in mobility (OR: 1.50, 95\% Cl: 1.17-1.92), toileting (OR: 1.30, 95\%Cl: $1.05-1.61)$, and dressing (OR: $1.23,95 \% \mathrm{Cl}: 1.02-1.48)$.

Conclusion: In the setting of modern stroke unit care, ESD appeared to have positive effects on stroke rehabilitation, in the subacute phase.

Keywords: Stroke, Early supported discharge, Rehabilitation, Patient reported outcome measurement

\section{Background}

Early supported discharge (ESD) with continued rehabilitation in the home has been shown to be beneficial among patients with mild to moderate stroke. The ESDmodel for rehabilitation was introduced in the late 1990s and includes an interdisciplinary team with appropriate recourses that coordinates the discharge and plan, supervise and continue the rehabilitation in the home environment [1]. This form of rehabilitation accelerates

\footnotetext{
* Correspondence: anna.brandal@umu.se

${ }^{1}$ Department of Public Health and Clinical Medicine, Umeå University, S-901

87 Umeå, Sweden

${ }^{2}$ Department of Community Medicine and Rehabilitation, Physiotherapy,

Umeå University, S-901 87 Umeå, Sweden

Full list of author information is available at the end of the article
}

the discharge from hospital, reduce long term dependency and admission to institutional care [1-4]. However, the criticism has been raised that most of the randomized controlled trials on ESD services were published more than 10 years ago $[5,6]$. Today, the majority of patients are being discharged home early after stroke, due to access of hyper-acute therapies, and implement early interventions for carotid stenosis. There is a need to evaluate efficacy and safety of ESD in current stroke care settings and to adapt ESD service to local conditions for appropriate implementation $[1,5,6]$.

In Sweden, the majority (91\% in 2014) of patients with stroke are cared for at a stroke unit (http://www.riksstroke.org), but there has been no major expansion of 
ESD. Despite recommendations in the National Guidelines for stroke care [7], the proportion of patients with stroke that receive ESD after stroke unit care has varied, dramatically across Sweden. Västerbotten County (Umeå Stroke Center and Skellefteå hospital) is one of the counties with high a proportion of ESDs (http://www.riks-stroke.org, [8]).

We previously described the method, content, and outcome of ESDs according to the Umeå Stroke Center model in Västerbotten County [9]. This model showed that it was possible to adopt and implement ESD for patients with stroke in Umeå. The model included important key elements for an effective ESD service [6, 8], such as a multidisciplinary team with experience in stroke rehabilitation, appropriate resources, periodic team meetings, and continuous evaluations of outcome with standardized measurements. Our previous results showed that ESD services reduced patient dependence in activities in daily living (ADL) and increased patient mobility, without increasing the risk of accidental falls or other injuries [9]. The patients were very satisfied with the ESD-service. However, that observational implementation study did not include a control group.

The present study aimed to evaluate patient-reported outcomes measures (PROMs) among patients with stroke that received modern stroke unit care, and compare PROMs between those that received or did not receive ESD. The ESD was delivered according to a previously described model [9]. We hypothesized that patients that received ESD would exhibit improved PROMs regarding satisfaction with rehabilitation (primary outcome), activity in daily living (ADL), tiredness/ fatigue, pain, dysthymia/depression, general health status and information about stroke (secondary outcomes) compared to controls.

\section{Methods}

For this case control, observational study, we retrieved data from the Swedish Stroke Registry, Riksstroke [10], and from the Longitudinal Integration Database for Health Insurance and Labor Market Studies (LISA). Information from the Swedish Stroke Registry was linked to the LISA database through personal identification numbers. This study was approved by the Regional Ethics Review Board at Umeå University (Dnr 2012-179-32 M, 2014-273-32 M).

\section{Register}

Currently, all 72 hospitals that treat patients with acute stroke participate in the Swedish Stroke Registry, Riksstroke [10], which started in 1994. The primary aim of Riksstroke is to monitor and support improvements in the quality and implementation of new methods in stroke care in Sweden. The registry includes patients with ischemic and hemorrhagic stroke and data on first-ever and recurrent strokes. The acute phase questionnaire of Riksstroke contains basic patient characteristics (age, sex, living conditions, history of previous stroke, and comorbidities), diagnosis, level of consciousness on arrival, pharmaceutical treatments, complications, and the sequence of care (type of stroke care, organization, and department). In Riksstroke the hospitals that care for patients with acute stroke have been divided into three categories: university hospitals (9 pcs), specialized nonuniversity hospitals (23 pcs) and community hospitals (40 pcs) [11]. Riksstroke also includes 3-month and 12-month follow up questionnaire that describe patient-reported outcomes and rehabilitation after stroke. The 3-month and 12-month questionnaire is administrated by the hospitals and filled in by the patients.

The LISA database at Statistics Sweden includes information on all Swedish citizens, starting at 16 years of age. In particular, it includes socioeconomic factors, like disposable income, education, and country of birth.

\section{Participants and setting}

All patients registered in the Riksstroke registry with a first-ever diagnosis of acute stroke between 1 January, 2010 and 31 December 2013 were included in the present study, when they fulfilled the following criteria: diagnosis of ischemic or hemorrhagic stroke; mild to moderate stroke severity at admission (measured as level of consciousness on a scale of $1-3$, according to the Reactive Level Scale, RLS85) [12]; living at home; and independency in ADL at stroke onset. Patients that met the inclusion criteria were divided into an ESD intervention group and a control group (Fig. 1).

\section{ESD intervention group}

Västerbotten County have three hospitals with different primary catchment areas that cared patients in acute and sub-acute phases of stroke. Two of these hospitals, the Umeå Stroke Center (university hospital) and Skellefteå hospital (community hospital) had similar organizations regarding stroke care. Both hospitals had stroke unit care followed by ESD according to a previously described model [9]. These hospitals provided ESD to a comparatively large proportion of patients $(41.2 \%$ at Umeå Stroke Center and $57.5 \%$ at Skellefteå hospital) compared to other hospitals in Sweden. The intervention group (ESD group) consisted of consecutive patients with stroke that received modern stroke unit care, followed by the ESD-service. During the study period, ESD was delivered to $41.2 \%$ of all patients with stroke admitted to the Umeå Stroke Center and 57.5\% admitted to Skellefteå. Patients with severe stroke and those who died during hospitalization were not included in the ESD intervention group. 


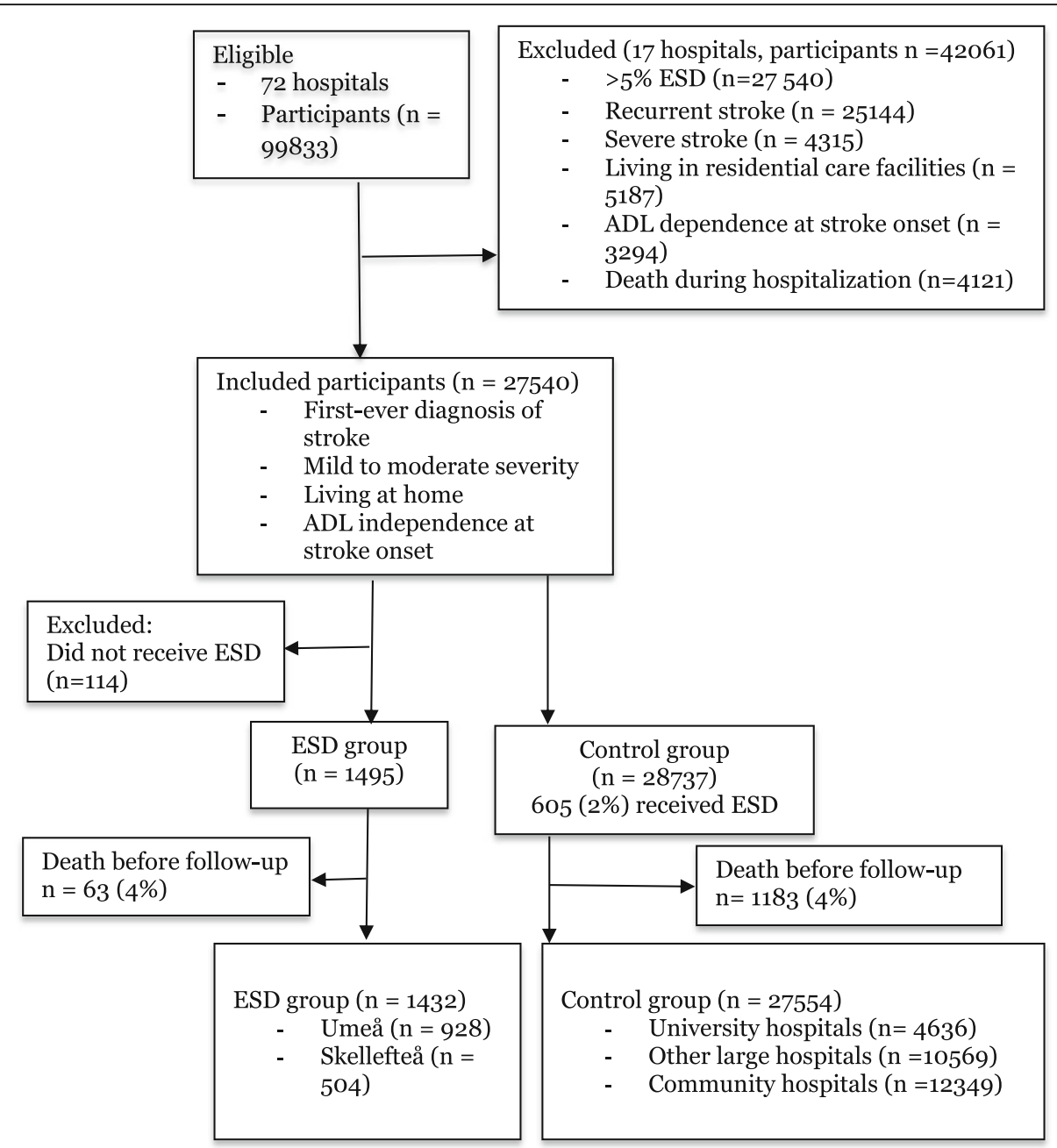

Fig. 1 Flow chart of the study inclusion procedure. ESD: early supported discharge

\section{Control group}

The control group consisted of patients treated at stroke units in hospitals that cared for patients with acute stroke. At these hospitals, a low $(<5 \%$ of all stroke patients) proportion of patients were given ESD. Therefore, the control group, which fulfilled the same inclusion criteria as the intervention group also included some patients that received ESD $(<5 \%)$. Patients with severe stroke and those who died during hospitalization were not included in the control group. Hospitals in Sweden that only partially implemented ESD (5-20\% of stroke patients) and those who registered other models of home rehabilitation were excluded.

\section{Variables}

Patient characteristics for both groups included sex, age, stroke subtype, treatment with thrombolysis, domestic companions, mobility, hypertensive treatment, diabetes, atrial fibrillation, and smoking before stroke onset. The level of consciousness upon admission and the length of hospital stay were also considered baseline characteristics of the two groups. These variables were retrieved from the Riksstroke registry. Information on education and country of birth was retrieved from the LISA database. The level of education was classified as primary school, secondary school, or university level. Country of birth was categorized as Sweden, Nordic countries (Sweden excluded), Europe (Nordic countries excluded), or other countries.

The outcome variables for this study were PROM results from the 3-months follow up recorded in Riksstroke. The primary outcome was satisfaction with the rehabilitation after discharge. Secondary outcome variables were; satisfaction with information provided about stroke, tiredness/fatigue, pain, dysthymia/depression, general health status and ADL dependence (mobility, toileting, and dressing). Data from the PROM values recorded in Riksstroke at the 3-months follow up have been validated against 
established measurements with the finding of accurate reliability (http://www.riks-stroke.org).

Some questions had multiple choice responses, and for our analysis, the responses were dichotomized. For example, patients were asked the questions: "How satisfied or dissatisfied are you with the rehabilitation or training you received after your stay in the hospital?" and "How satisfied or dissatisfied are you with the stroke information provided?"; and they responded with one of the following options: very satisfied, satisfied, dissatisfied, very dissatisfied, no need of rehabilitation, needed, but did not receive rehabilitation, or I do not know. And dependent categories were taken as reference (code = ref) for variables measuring a favourable outcome (satisfaction with rehabilitation, information about stroke, general health and Adl function) When assessing outcome variables that means an unfavourable result (tiredness/fatigue, pain, depression) we used a 'positive' reference $($ code $=$ ref $)$.

Similarly, the questions: "Do you feel tired/fatigue?", "Do you have any pain?", and "Do you feel depressed?" had response options; never, almost never, sometimes, often, constantly, or do not know, and they were coded as often or seldom (ref). The "often" code was assigned to: sometimes, often, constantly, and missing. The question "How would you assess your general health?" had response options: very good, somewhat good, somewhat poor, very poor, and they were coded good or poor(ref). The "poor" code was assigned to somewhat poor, very poor, and do not know.

Finally, responses to the ADL questions were coded as independent and dependent (ref), as follows. The question: "How is your mobility now?" had response options: "I can get around by myself indoors and outdoors" (independent), "I can get around by myself indoors, but not outdoors" (independent), "I need assistance when I want to move around" (dependent), or "I do not know" (dependent). The question: "Do you need assistance when visiting the toilet?" had response options: "I can manage visiting the toilet by myself" (independent) and "I need assistance when visiting the toilet" (dependent). The question "Do you need assistance getting dressed and undressed?" had response option: "I can manage to get dressed and undressed by myself", (independent) and "I need assistance getting dressed and undressed" (dependent).

\section{Statistical analysis}

Baseline characteristics for the ESD and control groups are expressed as frequencies and proportions, for categorical data, and as the mean and standard deviation $(\mathrm{SD})$, for continuous variables. Baseline values were compared between groups with the independent $t$-test (for continuous variables) and the chi-square test (for categorical variables). The association between PROMs and ESD were analysed in separate multivariable logistic regression models. These models assessed the probability of satisfaction with rehabilitation after discharge, satisfaction with the information provided about stroke, tiredness/fatigue, pain, dysthymia/depression, general health status, and ADL dependency (mobility, toilet hygiene, and dressing) in the ESD group compared to the control group. In addition to the group effect (ESD or control), each model included the independent factors that were significant in the baseline comparison: age (continuous), thrombolysis, smoking, atrial fibrillation, country of birth, and education. The results are presented as the odds ratio (OR) with a 95\% confidence interval $(95 \% \mathrm{CI})$. The confidence intervals and $P$-values were not adjusted for multiple testing. Sensitivity analyses were performed where the missing data (missing or unknown) were included in the reference category. Subgroup analyses were performed to compare data for Umeå Stroke Center with other university hospitals and Skelleftea hospital with community hospitals. In the subgroup analysis, missing data were included in the reference category. The analyses were performed with IBM SPSS Statistics 21 statistical software.

\section{Results}

Between 1 January 2010 and 31 December 2013, 99,833 patients whereof 74,689 with a first-ever diagnosis of acute stroke were registered in the Riksstroke. Of these patients, 30,232 were included in this study (Fig. 1). During these years, the coverage rate in The Riksstroke varies from 88 to 91\%. The ESD group comprised of 1495 participants that received ESD treatment after stroke unit care at the Umeå Stroke Center (university hospital) and at Skelleftea hospital (community hospital). The control group comprised 28,737 participants treated at 3 university hospitals, 13 other large hospitals, and 39 community hospitals. The control group were treated at stroke units where a very low proportion (605 participants, 2\%) received ESD. Participants in the ESD group were slightly younger, had a higher education level and were more often born in Sweden than participants in the control group. The ESD group had lower frequencies of smoking and atrial fibrillation and a higher frequency of thrombolysis than the control group (Table 1).

Three months after a stroke, 28,986 participants remained alive: 1432 (96\%) were in the ESD group and 27,554 (96\%) were in the control group. Due to differences between the ESD and control participants in the ESD groups at baseline the multivariable logistic regression models of PROMs were adjusted for age, thrombolysis, smoking, atrial fibrillation, country of birth, and education. The analysis showed that the ESD compared with the control group were more satisfied with 
Table 1 Baseline characteristics of study participants $(n=30,232)$

\begin{tabular}{|c|c|c|c|}
\hline \multirow[t]{2}{*}{ Variable } & \multirow{2}{*}{$\begin{array}{l}\text { ESD group } \\
(n=1495)\end{array}$} & \multirow{2}{*}{$\begin{array}{l}\text { Control group } \\
(n=28,737)\end{array}$} & \multirow[t]{2}{*}{$p$ value } \\
\hline & & & \\
\hline Sex, n (\%) & & & 0.212 \\
\hline Males & $829(55.5)$ & $15,461(53.8)$ & \\
\hline Females & $666(44.5)$ & $13,276(46.2)$ & \\
\hline Age, mean (SD) & $73(12.8)$ & $74(12.4)$ & 0.001 \\
\hline Stroke subtype, n (\%) & & & 0.244 \\
\hline Ischemic Stroke & $1314(87.9)$ & $25,646(89.2)$ & \\
\hline Intracerebral hemorrhage & $159(10.6)$ & $2741(9.5)$ & \\
\hline Undetermined & $22(1.5)$ & $350(1.2)$ & \\
\hline Thrombolysis, n (\%) & $212(14.2)$ & $2252(7.8)$ & 0.001 \\
\hline Missing & $1(0.1)$ & $142(0.5)$ & \\
\hline Living alone, n (\%) & $605(40.5)$ & $12,428(43.2)$ & 0.091 \\
\hline Missing data & $4(0.3)$ & $97(0.3)$ & \\
\hline Mobility, n (\%) & & & 0.249 \\
\hline Independent indoors- and outdoors & $1468(98.2)$ & 28,088 (97.7) & \\
\hline Independent indoors & $27(1.8)$ & $649(2.3)$ & \\
\hline Hypertension, n (\%) & $817(54.6)$ & $16,430(57.2)$ & 0.076 \\
\hline Missing data & $3(0.2)$ & $107(0.4)$ & \\
\hline Diabetes, n (\%) & $250(17.4)$ & $5254(18.3)$ & 0.106 \\
\hline Missing data & $0(0.0)$ & $40(0.1)$ & \\
\hline Atrial fibrillation, n (\%) & $282(18.9)$ & $6847(23.8)$ & 0.001 \\
\hline Missing data & $0(0.0)$ & $102(0.4)$ & \\
\hline Smoking, n (\%) & $157(10.5)$ & $4331(15.1)$ & 0.001 \\
\hline Missing data & $36(2.4)$ & $2001(7.0)$ & \\
\hline Level of consciousness on admission, n (\%) & & & 0.123 \\
\hline RLS 1 & $1391(93.0)$ & $26,419(91.9)$ & \\
\hline RLS 2-3 & $104(7.0)$ & $2318(8.1)$ & \\
\hline Length of hospital stay (SU), median (Q1-Q2) & $5(3-10)$ & $6(3-13)$ & 0.920 \\
\hline Missing data & $50(3.3)$ & $1220(4.2)$ & \\
\hline Education, n (\%) & & & 0.001 \\
\hline Primary School & $527(35.3)$ & $11,902(41.4)$ & \\
\hline Secondary School & $590(39.5)$ & $9930(34.6)$ & \\
\hline University & $259(17.3)$ & $4428(15.4)$ & \\
\hline Missing data & $119(7.9)$ & $2470(8.6)$ & \\
\hline Country of birth, $n(\%)$ & & & 0.001 \\
\hline Sweden & $1431(95.7)$ & 25,392 (88.4) & \\
\hline Nordic countries ${ }^{a}$ & $41(2.7)$ & $1436(5.0)$ & \\
\hline Europe $^{b}$ & $11(0.8)$ & $1234(4.3)$ & \\
\hline Other countries & $9(0.6)$ & 466 (1.6) & \\
\hline Missing data & $3(0.2)$ & $209(0.7)$ & \\
\hline
\end{tabular}

SU - Stroke unit

a Except Sweden

${ }^{\mathrm{b}}$ Except Nordic Countries 
rehabilitation after discharge $(p<0.004$, OR $1.78,95 \%$ CI: 1.17-2.49), showed more independence in mobility $(p<0.001$, OR $1.50,95 \% \mathrm{CI}: 1.17-1.92)$, toileting $(p<0.016$, OR $1.30,95 \%$ CI: $1.05-1.61)$, and dressing $(p<0.03$, OR 1.23, 95\% CI: $1.02-1.48)$, and felt less dysthymia/depression $(p<0.001$, OR $0.68,95 \%$ CI: $0.55-0.84$ ) (Table 2). There were no significant differences between the groups in the information received about stroke, tiredness/fatigue, pain or general health status (Table 2).

The proportions of missing responses were higher in the ESD group for all variables $(14.1-26.9 \%$ missing responses) than in the control group (11.8-22.6\% missing responses). In a sensitivity analysis, where missing/unknown/no need responses were included in the reference category, the ESD group remained more satisfied with rehabilitation after discharge $(p<0.001$, OR $1.26,95 \%$ CI: $1.10-1.43)$ and felt less depressed $(p<0.001$, OR 0.68, 95\% CI: $0.55-0.84)$ than controls, but the groups were not significantly different in the other variables (Table 3).

In the subgroup analyses of data form the Umea Stroke Center (ESD subgroup 1) and other university hospitals (control subgroup 1), we found that the ESD group 1 was more satisfied with the rehabilitation $(p<$ 0.0001, OR2.27, 95\% CI: 1.44-3.59) and stroke information provided $(p<0,001$, OR 1.93, 95\% CI: $1.32-2.37)$ and experienced less depression $(p<0.001$, OR $0.55,95 \%$ CI: 0.41-0.75), and were better in Adl function than the control subgroup 1 (Table 4). In the subgroup analysis of data from Skellefteå hospital (ESD subgroup 2) and other community hospitals (control subgroup 2), there were no significant differences. (Table 4).

\section{Discussion}

This case-control observational study based on the Swedish stroke registry, Riksstroke, revealed that ESD provided significant benefits to patients with stroke treated in modern stroke care units. Those that received ESD experienced more satisfaction with rehabilitation after discharge, less need for assistance with ADL, and less dysthymia/depression, compared to patients that did not receive ESD.

The outcomes of this study were based on the responses to PROMs. PROMs evaluate a person's feeling: it includes symptom reporting, satisfaction with care and treatments, self-rated health, and health-related quality of life [13]. In a large registry with national coverage (Riksstroke), it is important to choose simple questions that cannot be misunderstood. Rikstroke has developed simplified PROMs for dysthymia/depression, fatigue, pain, general health status and ADL (mobility, toileting and dressing). These PROMs have been validated against more established measurements (http://www.riks-stroke.org). The validation showed good agreement with established measurements and accurate reliability for the variables chosen in this study (http://www.riks-stroke.org, [14]).

In the current study, it was possible to identify and exclude those who did not receive ESD in the intervention group, but it was not technically possible in the control group. About 2\% of the participants in the control group had received ESD, according to Rikstroke data. These participants were distributed throughout the control hospitals, and the majority of hospitals reported only a few participants/year. It is possible that these registrations are incorrect and we assumed that these patients had not received rehabilitation according to an established model for ESD and that including these patients would not affect our analysis.

Patient satisfaction regarding ESD has previously been evaluated, but those studies reported conflicting results. Some studies showed improved satisfaction with ESD [1, 15] and others found insufficient evidence [8]. Patient satisfaction may be affected by various factors, particularly homecoming experiences and patient expectations. Some studies have investigated patient experiences in homecoming and home rehabilitation in the context of ESD [16-18]. Those studies indicated that patients and their families were positive to coming home, and they expressed great satisfaction about receiving rehabilitation within the home environment. The patients felt more capable of undertaking ADL in the home environment, and they were looking forward to re-establishing meaningful participation in their chosen life roles [16]. Previous research has also reported that domiciliary therapy allowed patients and their families to become more involved in decision-making, to provide more insight, and to offer motivation in rehabilitation functions [19].

Another aspect of satisfaction with rehabilitation is the patient's expectations of coming home with ESD after stroke. A recent study [20] on the expectations of coming home with very early supported discharge and home rehabilitation after stroke found that the participants had mixed expectations. Patients were longing to come home, but also described insecurity and fear. Despite these mixed expectations, the participants were highly confident that the ESD team would support them in achieving independence [20]. Presumably, patient satisfaction was closely linked to their participation in rehabilitation. Thus, it was important that patient expectations were consistent with the intervention received.

A strength of this study was the large control group, which was drawn from many different hospitals covered in Riksstroke. Another strength was the use of two registries, which provided information about both patient characteristics, education level, and country of birth. We 
Table 2 Multiple logistic regression of patient reported outcome variables 3 months after stroke

\begin{tabular}{|c|c|c|c|c|c|c|}
\hline \multicolumn{2}{|c|}{$(n=28,986)$ Odds ratio (OR) with $95 \%$ confidence interval } & \multirow{3}{*}{$\begin{array}{l}\text { Control group } \\
(n=27,554)\end{array}$} & \multirow{3}{*}{$p$ value } & \multirow{3}{*}{ OR } & \multirow[b]{2}{*}{$95 \% \mathrm{Cl}$} & \multirow[b]{3}{*}{ Upper } \\
\hline Variable & ESD group & & & & & \\
\hline & $(n=1432)$ & & & & Lower & \\
\hline \multicolumn{7}{|c|}{ Satisfaction with rehabilitation ${ }^{a}, \mathrm{n}(\%)$} \\
\hline Satisfied & $507(35.4)$ & $9182(33.3)$ & 0.001 & 1.78 & 1.17 & 2.49 \\
\hline Dissatisfied & $47(3.3)$ & $1405(5.1)$ & & ref & & \\
\hline No need & 449 (31.4) & $9231(33.5)$ & & & & \\
\hline Not received & $44(3.1)$ & $1501(5.4)$ & & & & \\
\hline Missing and do not know & $385(26.9)$ & $6235(22.6)$ & & & & \\
\hline \multicolumn{7}{|c|}{ Information provided about stroke, n (\%) } \\
\hline Satisfied & $927(64.7)$ & $16,820(61.0)$ & 0.533 & 1.08 & 0.85 & 1.37 \\
\hline Dissatisfied & $82(5.7)$ & $1700(6.2)$ & & ref & & \\
\hline No need & $87(6.1)$ & $3256(11.8)$ & & & & \\
\hline Missing and do not know & $336(23.5)$ & $5778(21.0)$ & & & & \\
\hline \multicolumn{7}{|l|}{ Tiredness/fatigue, n (\%) } \\
\hline Seldom & $780(54.5)$ & $15,440(56.0)$ & & ref & & \\
\hline Often & $410(28.6)$ & 8595 (31.2) & 0.748 & 0.98 & 0.86 & 1.11 \\
\hline Missing & $242(16.9)$ & 3519 (12.8) & & & & \\
\hline \multicolumn{7}{|l|}{ Pain, n (\%) } \\
\hline Seldom & $956(66.8)$ & $19,117(69.4)$ & & ref & & \\
\hline Often & $217(15.2)$ & $4745(17.2)$ & 0.523 & 0.95 & 0.814 & 1.11 \\
\hline Missing & $259(18.1)$ & $3692(13.4)$ & & & & \\
\hline \multicolumn{7}{|l|}{ Depression, n (\%) } \\
\hline Seldom & $1083(75.6)$ & 20,819 (75.6) & & ref & & \\
\hline Often & $109(7.6)$ & $3118(13.3)$ & 0.001 & 0.68 & 0.55 & 0.84 \\
\hline Missing & $240(16.8)$ & $3617(13.1)$ & & & & \\
\hline \multicolumn{7}{|l|}{ General health, n (\%) } \\
\hline Good & $988(69.0)$ & $19,163(69.5)$ & 0.091 & 1.15 & 0.98 & 1.35 \\
\hline Poor & $200(14.0)$ & 4779 (17.3) & & ref & & \\
\hline Missing & $244(17.0)$ & $3612(13.1)$ & & & & \\
\hline \multicolumn{7}{|l|}{ Adl-independence, n (\%) } \\
\hline \multicolumn{7}{|l|}{ Mobility } \\
\hline Independent & $1146(80.0)$ & 21,722 (78.8) & 0.001 & 1.50 & 1.17 & 1.92 \\
\hline Dependent & $83(5.8)$ & $2564(9.3)$ & & ref & & \\
\hline Missing & 203 (14.2) & 3268 (11.9) & & & & \\
\hline \multicolumn{7}{|l|}{ Toileting } \\
\hline Independent & 1117 (78.0) & 21,236 (77.1) & 0.016 & 1.30 & 1.05 & 1.61 \\
\hline Dependent & $112(7.8)$ & 3247 (11.8) & & ref & & \\
\hline Missing & $203(14.2)$ & 3247 (11.8) & & & & \\
\hline \multicolumn{7}{|l|}{ Dressing } \\
\hline Independent & 1075 (75.1) & 20,394(74.0) & 0.030 & 1.23 & 1.02 & 1.48 \\
\hline Dependent & 155 (10.8) & 3895 (14.1) & & ref & & \\
\hline Missing & $202(14.1)$ & 3265 (11.8) & & & & \\
\hline
\end{tabular}

${ }^{\text {a After Discharge }}$ 
Table 3 Patient-reported outcome variables, 3 months after stroke $(n=28,986)$ (sensitivity analysis)

\begin{tabular}{|c|c|c|c|c|c|c|}
\hline \multirow[t]{2}{*}{ Variable } & \multirow{2}{*}{$\begin{array}{l}\text { ESD group } \\
(n=1432)\end{array}$} & \multirow{2}{*}{$\begin{array}{l}\text { Control group } \\
(n=27,554)\end{array}$} & \multirow[t]{2}{*}{$p$ value } & \multirow[t]{2}{*}{$\mathrm{OR}$} & \multicolumn{2}{|l|}{$95 \% \mathrm{Cl}$} \\
\hline & & & & & Lower & Upper \\
\hline \multicolumn{7}{|c|}{ Satisfaction with rehabilitation ${ }^{\mathrm{a}}, \mathrm{n}(\%)$} \\
\hline Satisfied & $507(35.4)$ & $9182(33.0)$ & 0.001 & 1.26 & 1.10 & 1.43 \\
\hline Dissatisfied $^{b}$ & $925(64.6)$ & $18,372(67.0)$ & & ref & & \\
\hline \multicolumn{7}{|c|}{ Information provided about stroke, n (\%) } \\
\hline Satisfied & $927(64.7)$ & $16,820(61.0)$ & 0.444 & 1.05 & 0.93 & 1.17 \\
\hline Dissatisfied $^{\mathrm{b}}$ & $505(35.3)$ & $10,734(39.0)$ & & ref & & \\
\hline \multicolumn{7}{|l|}{ Tiredness/fatigue, n (\%) } \\
\hline Seldom & $780(54.5)$ & $15,440(56.0)$ & & ref & & \\
\hline Often and missing & $652(45.5)$ & $12,114(44.0)$ & 0.750 & 0.98 & 0.66 & 1.11 \\
\hline \multicolumn{7}{|l|}{ Pain, n (\%) } \\
\hline Seldom & $956(66.8)$ & $19,117(69.4)$ & & ref & & \\
\hline Often and missing & $476(33.2)$ & 8437 (30.6) & 0.523 & 0.95 & 0.81 & 1.11 \\
\hline \multicolumn{7}{|l|}{ Depression, n (\%) } \\
\hline Seldom & $1083(75.6)$ & $20,819(75.6)$ & & ref & & \\
\hline Often and missing & $349(24.4)$ & $6735(24.4)$ & 0.001 & 0.68 & 0.55 & 0.84 \\
\hline \multicolumn{7}{|l|}{ General health, n (\%) } \\
\hline Good & $988(69.0)$ & $19,163(69.5)$ & & ref & & \\
\hline Poor and missing & $444(31.0)$ & $8391(30.5)$ & 0.090 & 0.87 & 0.74 & 1.02 \\
\hline \multicolumn{7}{|l|}{ Adl-independence, n (\%) } \\
\hline \multicolumn{7}{|l|}{ Mobility } \\
\hline Independent & $1109(93.0)$ & $21,722(78.8)$ & 0.001 & 0.78 & 0.68 & 0.90 \\
\hline Dependent and missing & $323(22.5)$ & $5832(21.2)$ & & ref & & \\
\hline \multicolumn{7}{|l|}{ Toileting } \\
\hline Independent & $1132(78.9)$ & $21,236(77.1)$ & 0.001 & 0.78 & 0.68 & 0.88 \\
\hline Dependent and missing & $352(24.5)$ & $6318(22.9)$ & & ref & & \\
\hline \multicolumn{7}{|l|}{ Dressing } \\
\hline Independent & $1077(75.2)$ & 20,394(74.0) & 0.001 & 0.81 & 0.71 & 0.92 \\
\hline Dependent and missing & $355(24.8)$ & $7169(26.0)$ & & ref & & \\
\hline
\end{tabular}

${ }^{\text {a After Discharge }}$

${ }^{\mathrm{b}}$ Dissatisfied includes very dissatisfied, dissatisfied, in need, but did not received rehabilitation, I do not know and missing

adjusted for variables that were measured in Riksstroke and differed in the baseline comparison, but as in all observational studies, there is a possibility of unmeasured confounding. Since we expected the outcome variables to be correlated, we chose not to adjust the confidence level for multiple testing. Using Bonferroni correction, which is a conservative method, we would still report significant results for outcome with $p$-values $<0.005$ (all but toileting and dressing).

A limitation in Rikstroke in general is a limited response rate of NIHSS at baseline thus excluding detailed description of stroke severity. In a previous observational implementation study describing the ESD at Umeå Stroke Center, a modified version of the NIHSS at admission that included level of consciousness, arm and leg paresis and language showed a mean value of $2 \pm 2.2$ (SD). In this study we aimed to model positive outcome. In general, there were more missing responses in the ESD group. In the sensitivity analysis (Table 3) we included missing responses in the negative category (which corresponds to a worst-case scenario). This analysis showed similary results as the main analysis in Table 2. The lack of response may be due to different causes. In this study, about $30 \%$ of the participants in the ESD group reported that they had no need of rehabilitation after discharge. However, according to information in the Riksstroke Registry, all individuals in the ESD group received rehabilitation efforts. This highlight the difficulty of collecting PROM responses at 3 months after a stroke onset. After a stroke, it is not unusual for 
Table 4 Subgroups analysis of patient-reported outcome variables 3 months after stroke $(n=18,417)$

\begin{tabular}{|c|c|c|c|c|c|c|c|c|}
\hline \multirow[b]{2}{*}{ Variable } & \multicolumn{2}{|c|}{ University hospital } & \multirow[b]{2}{*}{$p$ value } & \multirow[b]{2}{*}{ OR $(95 \% \mathrm{Cl})$} & \multicolumn{2}{|c|}{ Small hospitals } & \multirow[b]{2}{*}{$p$ value } & \multirow[b]{2}{*}{ OR $(95 \% \mathrm{Cl})$} \\
\hline & $\begin{array}{l}\text { ESD } 1 \\
(n=928)\end{array}$ & $\begin{array}{l}\text { Control } 1 \\
(n=4636)\end{array}$ & & & $\begin{array}{l}\text { ESD } 2 \\
(n=504)\end{array}$ & $\begin{array}{l}\text { Control } 2 \\
(n=12,349)\end{array}$ & & \\
\hline \multicolumn{9}{|c|}{ Satisfaction with rehabilitation*, n (\%) } \\
\hline Satisfied & $338(36.4)$ & $1658(35.8)$ & 0.001 & $2.27(1.44-3.58)$ & $169(33.5)$ & 4024 (32.6) & 0.863 & $1.04(0.66-1.64)$ \\
\hline Dissatisfied & $25(2.7)$ & $278(6.0)$ & & ref & $22(4.4)$ & $593(4.8)$ & & ref \\
\hline No need & $267(28.8)$ & $1342(28.9)$ & & & $182(36.1)$ & 4401 (35.6) & & \\
\hline Not received & $20(2.2)$ & $215(4.6)$ & & & $24(4.8)$ & $732(5.9)$ & & \\
\hline Missing and do not know & $278(30.0)$ & $1143(24.7)$ & & & $107(21.2)$ & $2599(21)$ & & \\
\hline \multicolumn{9}{|l|}{ Information about stroke, n (\%) } \\
\hline Satisfied & $590(63.6)$ & $2626(56.6)$ & 0.001 & $1.93(1.32-2.73)$ & $337(66.9)$ & $7683(62.2)$ & 0.06 & $0.63(0.45-0.88)$ \\
\hline Dissatisfied & $38(4.1)$ & $337(7.3)$ & & ref & $44(8.7)$ & $676(5.5)$ & & ref \\
\hline No need & $52(5.6)$ & $595(12.8)$ & & & $35(6.9)$ & $1531(12.4)$ & & \\
\hline Missing and do not know & $248(26.7)$ & $1078(23.3)$ & & & $88(17.5)$ & $2459(9,19)$ & & \\
\hline \multicolumn{9}{|l|}{ Tiredness/fatigue, n (\%) } \\
\hline Seldom & $470(50.6)$ & $2337(50.4)$ & & ref & $310(61.5)$ & $7256(58.8)$ & & ref \\
\hline Often & $252(27.2)$ & $1553(33.5)$ & 0.117 & $0.87(0.74-1.04)$ & $150(29.8)$ & $3622(29.3)$ & 0.860 & $0.98(0.80-1.20)$ \\
\hline Missing & $206(22.2)$ & $746(16.1)$ & & & $44(8.7)$ & $1471(11.9)$ & & \\
\hline \multicolumn{9}{|l|}{ Pain, n (\%) } \\
\hline Seldom & $586(63.1)$ & $3074(66.3)$ & & ref & $370(73.4)$ & 8794 (71.2) & & ref \\
\hline Often & $121(13.0)$ & $756(16.3)$ & 0.215 & $0.87(0.70-1.08)$ & $79(15.7)$ & $1942(15.7)$ & 0.976 & $1.04(0.78-1.29)$ \\
\hline Missing & $221(23.8)$ & $806(17.4)$ & & & $55(10.9)$ & $1613(13.1)$ & & \\
\hline \multicolumn{9}{|l|}{ Depression, n (\%) } \\
\hline Seldom & $660(71.1)$ & $3323(71.7)$ & & ref & $423(83.9)$ & 9586 (77.6) & & ref \\
\hline Often & $52(5.6)$ & $507(10.9)$ & 0.001 & $0.55(0.41-0.75)$ & $35(6.9)$ & $1104(8.9)$ & 0.09 & $0.73(0.51-1.05)$ \\
\hline Missing & $216(23,3)$ & $806(17.4)$ & & & $46(9.1)$ & 1659 (13.4) & & \\
\hline \multicolumn{9}{|l|}{ General health, n (\%) } \\
\hline Good & $604(65.1)$ & $3012(65.0)$ & 0.081 & $1.23(0.98-1.54)$ & $384(76.2)$ & 8847 (71.6) & 0.57 & $1.08(0.82-1.42)$ \\
\hline Poor & $110(11.9)$ & $743(16.0)$ & & ref & $67(13.3)$ & $1705(13.8)$ & & ref \\
\hline Missing & $214(23.1)$ & $881(19.0)$ & & & $53(10.5)$ & $1797(14.6)$ & & \\
\hline \multicolumn{9}{|l|}{ Adl-independence, n (\%) } \\
\hline \multicolumn{9}{|l|}{ Mobility } \\
\hline Independent & $683(73.6)$ & $3503(75.6)$ & 0.001 & $1.97(1.38-2.80)$ & $426(84.5)$ & 9868 (79.9) & 0.106 & $1.34(0.94-1.90)$ \\
\hline Dependent & $45(4.8)$ & $428(9.2)$ & & ref & $38(7.5)$ & $1214(9.8)$ & & ref \\
\hline Missing & $200(21.6)$ & $705(15.2)$ & & & $40(7.9)$ & $1267(10.3)$ & & \\
\hline \multicolumn{9}{|l|}{ Toileting } \\
\hline Independent & $670(72.2)$ & $3451(74.4)$ & 0.001 & $1.68(1.23-2.30)$ & $410(81.3)$ & 9609 (77.8) & 0.533 & $1.10(0.81-1.49)$ \\
\hline Dependent & $58(6.3)$ & $484(10.4)$ & & ref & $54(10.7)$ & 1475 (11.9) & & ref \\
\hline Missing & $200(21.6)$ & $701(15.1)$ & & & $1265(10.2)$ & $40(7.9)$ & & \\
\hline \multicolumn{9}{|l|}{ Dressing } \\
\hline Independent & $647(69.7)$ & 3319 (71.6) & 0.001 & $1.57(1.19-2.05)$ & $391(77.6)$ & $9219(74.7)$ & 0,856 & $0.98(0.75-1.27)$ \\
\hline Dependent & $80(8.6)$ & $618(13.3)$ & & ref & $75(14.9)$ & $1854(15.0)$ & & ref \\
\hline Missing & $201(21.7)$ & 699 (15.1) & & & $38(7.5)$ & $1276(10.3)$ & & \\
\hline
\end{tabular}


an individual to have problems, initially, with memory, concentration, and fatigue, and all these symptoms can affect the reliability of the PROM response. The lack of response can also be due to a wish to continue life and put the stroke incidence behind. In addition, it is important to consider a recall bias: that is, by the time a patient responds to the 3-months Riksstroke follow-up survey, it may be difficult to recall their experience with rehabilitation after discharge. Difficulties to recall their experience with rehabilitation after a long time and the fact that this is a fragile group, where the health can change is the reason for not including 12-months follow up in this study.

We found no differences between the ESD vs no ESD groups in pain or fatigue. This finding may be explained by the fact that a treatment recommendation was established for depression, but no consensus was established regarding the treatment of pain and/or fatigue.

Our results concerning ADL dependency were consistent with previously reported results. Patients that received ESD required less ADL assistance than patients that received modern conventional care without ESD $[1,8,21]$.

\section{Conclusions}

This case-control observational study, based on registry data of PROMs at 3-months follow up showed that patients that received ESD after stroke were more satisfied with rehabilitation after discharge and experienced less depression than patients that received other health care and/or rehabilitation care. In this study, all patients received modern stroke unit care with short hospital stays, access to hyper-acute therapies, and early carotid interventions. Therefore, our results substantiate the hypothesis that the previously shown benefits of ESD and home rehabilitation were also observed among patients treated in modern stroke care.

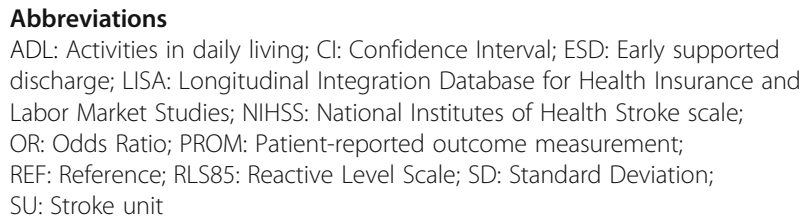

Abbreviations

ADL: Activities in daily living; $\mathrm{Cl}$ : Confidence Interval; ESD: Early supported discharge; LISA: Longitudinal Integration Database for Health Insurance and Labor Market Studies; NIHSS: National Institutes of Health Stroke scale; OR: Odds Ratio; PROM: Patient-reported outcome measurement; REF: Reference; RLS85: Reactive Level Scale; SD: Standard Deviation; SU: Stroke unit

\section{Acknowledgments}

We thank the members of the Rikstroke Collaboration (http://www.Rikstroke. org).

\section{Funding}

This study was supported by the Swedish Heart and Lung foundation, the Swedish Stroke Foundation, the Northern Swedish Stroke Fund, the County of Västerbotten, and the medical faculty of Umeå University.

\section{Availability of data and materials}

All data are available without restriction from corresponding author on reasonable request.

\section{Authors' contributions}

$A B, M E$, E-LG and PW designed and prepared the study. $A B$ analysed the data with advise from ME and PW. AB drafted the manuscript. ME, E-LG and PW advised on method of data analysis, presentation of results and critical revision of the manuscript. All authors read and approved the final manuscript.

Ethics approval and consent to participate

This study was approved by the Regional Ethics Review Board at Umeå University (Dnr 2012-179-32 M, 2014-273-32 M).

Consent for publication

Not applicable.

\section{Competing interests}

The authors declare that they have no competing interests.

\section{Publisher's Note}

Springer Nature remains neutral with regard to jurisdictional claims in published maps and institutional affiliations.

\section{Author details}

${ }^{1}$ Department of Public Health and Clinical Medicine, Umeå University, S-901 87 Umeå, Sweden. ²Department of Community Medicine and Rehabilitation, Physiotherapy, Umeå University, S-901 87 Umeå, Sweden. ${ }^{3}$ Department of Statistics, Umeå School of Business and Economics Umeå University, S-901 87 Umeå, Sweden. ${ }^{4}$ Department of Clinical Sciences, Karolinska Institute, Danderyd hospital, S-182 88 Stockholm, Sweden.

Received: 28 December 2017 Accepted: 5 March 2019

Published online: 12 March 2019

\section{References}

1. Fearon P, Langhorne P, Early Supported Discharge Trialists. Service for reducing duration of hospital care for acute stroke patients. Cochrane Database system Rev 2012; Issue 9. Art. No.: CD000443. doi: https://doi.org/ 10.1002/14651858.CD000443.pub3.

2. Langhorne P, Holmquist LW. Early Supported Discharge Trialists. Early supported discharge after stroke. J Rehabil Med. 2007;39:103-8.

3. Fjærtoft $H$, Rohweder $G$, Indredavik B. Stroke unit care combined with early supported discharge improves 5-year outcome: a randomized controlled trial. Stroke. 2011:42:1707-11.

4. Thorsén AM, Holmquist LW, de Pedro-Cuesta J, von Koch L. A randomized controlled trial of early supported discharge and continued rehabilitation at home after stroke: five-year follow-up of patient outcome. Stroke. 2005;36: 297-303.

5. Sunnerhagen KS, Danielsson A, Rafsten L, Björkdahl A, Axelsson ÅB, et al. Gothenburg very early supported discharge study (GOWED) NCTO1622205: block randomized trial with superiority design of very early supported discharge for patients with stroke. BMJ. 2013;13:66.

6. Fisher RJ, Gaynor C, Kerry M, Langhorne P, Anderson C, et al. A consensus of stroke: early supported discharge. Stroke. 2011;42:1392-7.

7. The National Board of health and welfare. National Guidelines for stroke care. 2009. (English version available at http://www.socialstyrelsen.se).

8. SBU. Rehabilitation at home after early supported discharge (ESD) for elderly patients after stroke. A systematic literature review. Stockholm: Swedish council on health technology assessment (SBU); 2015. SBU-rapport nr 234. ISBN 978-91-85413-77-5. (English version available at http://www.sbu.se

9. Bråndal A, Wester P. Stroke unit at home: a prospective observational implementation study for early supported discharge from the hospital. Int J Phys Med Rehabil. 2013;1:170. https://doi.org/10.4172/2329-9096.1000170.

10. Asplund K, Hulter-Åsberg K, Appelros P, Bjarne D, Eriksson M, Johansson $\AA$, Jonsson F, Norrving B, Stegmayr B, Terént A, Wallin S, Wester P. The Riksstroke story. Building a sustainable national register for quality assessment of stroke care. Int J Stroke. 2011;6:99-108.

11. Asplund K, Sukhova M, Wester P, Stegmayr B, Rikstroke Collaboration. Diagnostic procedures, treatment, and outcome in stroke patients admitted to different types of hospitals. Stroke. 2015;3:806-12. https://doi.org/10. 1161/STROKEAHA.114.007212.

12. Starmark JE, Stålhammar D, Holmgren E. The reaction level Svale (RLS85). Manual and guidelines. Acta Neurochir. 1988:91(1-2):12-20 PubMed PMID: 3394542. 
13. Jones JB, Snyder CF, Wu AW. Issues in the design of internet-based systems for collecting patient-reported outcomes. Qual Life Res. 2007;16(8):1407-17.

14. Glader E-L. Stroke care in Sweden. Hospital care and patients follow-up based on Riksstroke, the national quality register for stroke care. PhD Thesis, New Series NO. 838 2003. Umeå: Umeå University Medical Dissertations.

15. Ficher RJ, Cobley CS, Potgieter I, Moody A, Nouri F, Gaynor C, et al. Is stroke early supported discharge still effective in practice? A prospective comparative study. Clin Rehabil. 2015. https://doi.org/10.1177/ 0269215515578697.

16. Cobley CS, Fisher RJ, Chouliara KM, Walker MF. A qualitative study exploring patients and carers experiences of early supported discharge service after stroke. Clin Rehabil. 2013;27(8):750-7. https://doi.org/10.1177/ 0269215512474030.

17. Taule T, Raheim M. Life changed existentially: a qualitative study of experience at 6-8 months after mild stroke. Disabil Rehabil. 2014;36(25): 2107-19. https://doi.org/10.3109/09638288.2014.904448.

18. Taule T, Strand LI, Skouen JS, Raheim M. Striving for a life worth living: stroke survivors experience of home rehabilitation. Scand J Caring Sci. 2015. https://doi.org/10.1111/scs.12193.

19. Hiller S, Inglish-Jassiem G. Rehabilitation for community-dwelling people with stroke: home or Centre based? A systematic review. Int I Stroke. 2010; 5:178-86.

20. Nordin Å, Sunnerhagen KS, Axelsson ÅB. Patients' expectations of coming home with very early supported discharge and home rehabilitation after stroke - an interview study. BMC Neurol. 2015;15:235. https://doi.org/10. 1186/s12883-015-0492-0

21. Winkle A, Ekdahl C, Gard G. Early discharge to therapy-based rehabilitation at home in patients with stroke: a systematic review. Phys Ther Rev. 2008;13: $167-87$.

Ready to submit your research? Choose BMC and benefit from:

- fast, convenient online submission

- thorough peer review by experienced researchers in your field

- rapid publication on acceptance

- support for research data, including large and complex data types

- gold Open Access which fosters wider collaboration and increased citations

- maximum visibility for your research: over $100 \mathrm{M}$ website views per year

At $\mathrm{BMC}$, research is always in progress.

Learn more biomedcentral.com/submissions 